\title{
QUALIDADE PERCEBIDA EM BIBLIOTECA UNIVERSITÁRIA \\ NA ÓTICA DO USUÁRIO: emprego da abordagem teórico-metodológica \\ servqual em um serviço de referência
}

\begin{abstract}
Resumo: Avalia a qualidade dos serviços prestados no Serviço de Referência da Biblioteca Setorial do Centro de Artes da Universidade Federal do Espírito Santo (UFES) utilizando o método de Parasuraman, Zeithaml e Berry, o Servqual. Examina a matriz importância e satisfação como ferramenta para análise dos dados em relação às cinco dimensões da qualidade: Confiabilidade, Empatia, Garantia, Receptividade e Tangibilidade. A metodologia deste estudo possui caráter descritivo de natureza quantitativa e qualitativa. Seu delineamento é do tipo levantamento com a utilização de questionário online semiestruturado. Os resultados obtidos nesta pesquisa evidência que os clientes consideram a dimensão Receptividade importante, no entanto, há insatisfação. Outro diagnóstico demonstra que a percepção social do profissional bibliotecário e o acolhimento da biblioteca carecem de constantes cuidados, evidenciando desta forma a necessidade de ajustes sobre a qualidade de serviços. Recomenda o método Servqual para avaliação da qualidade de biblioteca acadêmica e, reconhece como ferramenta útil para a gestão e a tomada de decisões, o qual destaca pontos fortes e fracos das organizações, gerando informações sob a ótica da clientela.
\end{abstract}

Palavras-chave: Servqual. Serviço de Referência. Dimensões da qualidade. Biblioteca Acadêmica

\author{
Dulcinéa Sarmento Rosemberg \\ Doutora em Educação do Programa de Pós- \\ Graduação em Educação da Universidade \\ Federal do Espírito Santo (UFES), \\ projetoservqual@gmail.com \\ Marcelo Calderari Migue \\ marcelocalderari@yahoo.com.br
}

Sandra Maria Souza de Carvalho sandramsc@hotmail.com

\section{QUALITY PERCEIVED IN UNIVERSITY LIBRARY IN THE USER'S OPTICAL:} employment of the theoretical-methodological approach servqual in a reference service

\begin{abstract}
Evaluates the quality of services provided in the Reference Service of the Sectoral Library of the Arts Center of the Universidade Federal do Espírito Santo (UFES) using the method of Parasuraman, Zeithaml and Berry, the Servqual. Examines matrix at importance and satisfaction as a tool for data analysis in relation to the five dimensions of quality: Reliability, Empathy, Assurance, responsiveness and tangibility. The methodology of this study is kind of survey with the use of semistructured online questionnaire. The results of this research evidence that customers consider the Responsiveness dimension important, however, there is dissatisfaction. Another diagnostic demonstrates that the social perception of librarians and host require constant care requiring adjustments for an quality of service. Recommends the Servqual method to evaluate the quality of academic library and recognizes as a useful tool for management and decision making, highlights strong and weak points of the organizations, providing information from the perspective of customers.
\end{abstract}

Keywords: Servqual. Reference Services. Dimensions of quality. Academic Library. 


\section{INTRODUÇÃO}

$\mathrm{Na}$ era digital as bibliotecas físicas sobrevivem às Tecnologias de Informação e Comunicação (TIC). Por conta desse fato, a atuação dos bibliotecários tem sido um tema muito discutido na atualidade, especialmente, no que se refere a mudança de paradigma da "posse" para o "acesso" à informação. Assim, o trabalho dos bibliotecários precisa ser pautado pelo paradigma alternativo, isto é, o trabalho com foco nos usuários visando a prestação de serviços e produtos diferenciados.

Este trabalho se justifica pela relevância das discussões em torno da "qualidade de serviços de informação" e as possibilidades de contribuir, especificamente, para a melhoria do SR em Bibliotecas Acadêmicas. No presente artigo pretende-se abordar o seguinte problema: qual percepção e expectativa dos usuários acerca da qualidade do serviço de referência (SR) prestado pela Biblioteca Setorial de Artes (BSArtes) da Universidade Federal do Espírito Santo (Ufes), Campus de Goiabeiras, Vitória/ES. O objetivo principal da pesquisa é avaliar a qualidade dos serviços prestados no que tange a expectativa e a percepção dos usuários em relação ao SR da BSArtes, utilizando o Servqual (Service Quality Gap Analysis).

Em suma, ao dirigirmos o olhar para o estudo da qualidade do SR da BSArtes, o fazemos tendo em conta os seguintes aspectos da relevância desta pesquisa com os seus usuários: a) científico: visa contribuir como mais uma fonte de conhecimento sobre a qualidade do SR em uma biblioteca setorial de uma IES. b) institucional: o mapeamento das expectativas e das percepções dos usuários permitirá estabelecer uma política de atendimento à comunidade usuária. c) acadêmico: ampliar o entendimento sobre a qualidade de serviços prestados pela área de Biblioteconomia no que ser refere à importância e aperfeiçoamento de um SR. d) social: a tomada de decisão com base nos resultados obtidos poderá levar a melhoria do atendimento aos usuários, tornando a relação entre SR e os clientes, mais dinâmica e satisfatória.

\section{DIRECIONAMENTO DE SERVIÇOS E BIBLIOTECAS ACADÊMICAS}

Desde meados do século XX o discurso biblioteconômico vem apresentando em seu cerne preocupações com os usuários e não usuários. Além das necessidades expressas dos 
usuários, Lancaster (1996) diz ser imprescindível que a biblioteca compreenda as necessidades latentes que não se transformam em demandas, bem como as necessidades potenciais dos não-usuários sob o risco de ficar estagnada na prestação de serviços, o que representa estar em vias de obsolescência. Daí a enunciação das teses de Grogan (1995) e de Figueiredo (1999), que corroboram a importância do SR.

Lancaster (1996) considera a biblioteca um organismo em crescimento, aliás, uma das cinco leis ${ }^{1}$ de Ranganathan (2009). Tal processo envolve o acompanhamento das novas condições sociais e tecnológicas, que afetam significativamente a demanda pelos seus serviços. Alinhados com esse cenário, Vergueiro e Britto (2011) reportam que os profissionais da informação têm como premissa fornecer a informação correta e no momento certo ao usuário, outras duas leis de Ranganathan.

Para Grogan (1995, p. 33-34) o SR é um ato social, e também uma relação humana, por mais breve que seja, tem um status ímpar, caracterizando-se por envolver uma relação pessoal face a face, que torna o mais humano dos serviços da biblioteca; e, em segundo lugar pela certeza antecipada de que o "esforço despendido provavelmente não se desmanchará no ar"

Os trabalhadores responsáveis pelo SR consideram-no a pedra angular da prática ${ }^{2}$ profissional, sendo ele muito mais do que um serviço técnico especializado ou uma habilidade profissional, trata-se de uma atividade essencialmente humana que atende aos anseios de conhecer e compreender (GROGAN, 1995).Portanto o SR representa um eixo-conjunto importante das atividades em unidades de informação, uma vez que é nele que todas as atividades internas e externas da biblioteca resultam.

\subsection{GESTÃO UNIVERSITÁRIA, SERVIÇOS E QUALIDADE}

Nos últimos anos, a gestão universitária tem avançado na direção de um comprometimento com a qualidade dos serviços prestados. Esse movimento é percebido a partir de algumas leis e programas instituídos. Nessa direção. Brito e Vergueiro (2011)

1 As Cinco Leis da Biblioteconomia de S. R. Ranganathan são: 1. Livros são para usar. 2. Para cada leitor, seu livro. 3. Para cada livro, seu leitor. 4. Poupe o tempo do leitor. 5. A biblioteca é um organismo em crescimento. A quinta lei indica, segundo Lancaster, que a biblioteca deve estar preparada para se adaptar a novas condições, inclusive de se aprimorar para ao desenvolvimento social, regional e tecnológicos; mostrando habilidade para lidar com às necessidades mutáveis da clientela e com as necessidades potenciais dos ainda não usuários.

${ }^{2}$ Grogan (1995) aponta oitos processos abrangente contidos no SR: o problema, a necessidade de informação, a questão inicial, a questão negociada, a estratégia de busca, o processo de busca, a resposta e a solução. 
indicam que à Medida Provisória $n^{\circ}$ 147/2003, transformada na Lei $n^{\circ} 10.861 / 2004$, que instituiu o Sistema Nacional de Avaliação da Educação Superior (SINAES) tem com o objetivo de assegurar o processo nacional de avaliação das IES, dos cursos de graduação e do desempenho acadêmico de seus estudantes.

Almeida Júnior (2003) recomendam que os bibliotecários apliquem nos processos avaliativos definindo com clareza, delineando os instrumentos de avaliação de modo a responder questões específicas às suas inquietações e dos usuários. Agindo assim, a avaliação se faz necessária, pois é ela quem direciona qualquer mudança, transformação, realinhamento, manutenção e, até mesmo, o fim de uma ação. Sem avaliação, qualquer ação é exercida às cegas [...] (ALMEIDA JÚNIOR, 2003, p. 107)

Nessa perspectiva, existem várias razões para que os gestores incorporem práticas de avaliação em unidades de informação. Lancaster (1996) assinala quatro motivos para tal jeito de trabalhar: (I) estabelecer uma escala para mostrar em que nível de desempenho o serviço está funcionando no momento; (II) comparar o desempenho de várias bibliotecas ou serviços; (III) justificar sua existência simplesmente; e (IV) identificar as possíveis causas de insucessos ou ineficiência dos serviços ou ainda uma análise da relação custo-benefício (LANCASTER,1996).

\subsection{GESTÃO EM UNIDADES DE INFORMAÇÃO}

Para Almeida Júnior (2003) o usuário não pode ser entendido como um mero receptor dos serviços, antes é necessário compreende-lo como um participante ativo que auxilia a tomada de decisão. Enfim, ainda para o autor, o "outro lado importante que se traduz como alerta, é o fato de que não é o usuário o objeto de avaliação, mas o serviço do qual ele faz parte" (ALMEIDA JUNIOR, 2003, p. 203).

Reportando-se ao bibliotecário, Ferreira (1995) diz que esse profissional deve ter sensibilidade para entender as necessidades e limitações de seus clientes e assim, como gestor de um novo tipo de biblioteca, ele deve guiar a comunidade para a satisfação de suas necessidades informacionais. Em sintonia com essas premissas, Accart (2012, p. 114) lembra que "[...] um usuário satisfeito volta, se encontrar quem o ouça, quem lhe dê atenção e, naturalmente, a resposta certa para suas dúvidas [...]”. 
Por ser assim, adotamos o paradigma alternativo para realizar o presente estudo de usuários, que para Figueiredo (1999) coloca o usuário numa posição ativa, levando a ser o foco de atenção das unidades de informação.

\begin{abstract}
Desde o final da década de 1970, diversos pesquisadores envolveram na construção de modelos teóricos para entender melhor o processo pelo qual os usuários sentem necessidade e se engajam na busca e uso de informação. Sustentados por uma perspectiva cognitivista, autores como Belkin (1980), Wilson (1981), Dervin (1983), Taylor (1986), Elis (1989) e Kuhlthau (1991) começaram a desenvolver modelos para a compreensão do 'comportamento informacional' dos usuários. Esse conjunto de estudos recebeu o nome de "abordagem alternativa" (DERVIN; NILAN, 1986) por se contrapor ao outro modelo que entendia a informação como algo objetivo, dotado de sentido em si. Ao contrário, a abordagem alternativa buscava ver o que a informação é da perspectiva de quem a usa, do usuário. Essa perspectiva de quem foi introduzida no Brasil na metade da década de 1990 (FERREIRA, 1995; MARTUCCI, 1997). Desde então [...] a informação é entendida como um recurso usado por um sujeito diante de uma situação de lacuna ou estado vazio de conhecimento. (ARAÚJO, 2010, p. 25).
\end{abstract}

A abordagem alternativa (GONÇALVES 2013) e, mais recentemente, a social com seus desdobramentos e peculiaridades traz à tona um usuário em incessante processo de construção, livre para indicar o que deseja junto aos sistemas ou às conjunturas em que se situam, avaliando suas necessidades cognitivas, afetivas e fisiológicas próprias que coexistem dentro de uma ambiência institucional. Em suma, cabe lembrar o ditado do professor Antônio Houaiss, citado por Fonseca (2007, p. 97): "sempre haverá bibliotecários celestes e bibliotecários pedestres".

\title{
2.3 DIMENSIONAMENTO CONCEITUAL DE QUALIDADE EM SERVIÇOS
}

Britto e Vergueiro (2011) mostram que a preocupação com a qualidade de bens e serviços não é recente, teve início na década de 1920, com a criação do Controle Estatístico de Processo (CEP) e do Ciclo PDCA (Plan, Do, Ckeck e Act, ou planejar, executar, verificar e agir), chegando à gestão da qualidade total na década de 1950.

Já Parasuraman, Zeithaml e Berry (1985) iniciaram uma extensa pesquisa de natureza exploratória para ratificar os fatores determinantes da qualidade de serviço, abrangendo os seguintes objetivos: (a) rever o pequeno número de estudos existentes que investigaram qualidade de serviço; (b) divulgar os conhecimentos obtidos em uma extensa investigação exploratória de qualidade em quatro empresas de serviços; (c) desenvolver um modelo conceitual de qualidade de serviço; (d) oferecer propostas para estimular pesquisas futuras sobre a qualidade. 
Conceitualmente, a "qualidade" pode ser definida de distintas formas. Neste estudo escolheu-se o conceito de Parasuraman, Berry e Zeithaml (1985). Para esses autores, "qualidade" é a diferença entre as expectativas dos clientes sobre o serviço a receber e suas percepções sobre os serviços efetivamente recebidos.

Para Parasuraman, Zeithaml e Berry (1985), no julgamento de um serviço pode haver diferenças entre o que a biblioteca oferece e o que de fato o usuário necessita. Esse desalinhamento resulta tanto na falha da biblioteca em satisfazer as necessidades dos clientes como também nas expectativas irreais deles. Portanto não basta fornecer serviços com excelente qualidade, é necessário que as organizações estruturem processos contínuos para monitorar as percepções dos clientes sobre a sua qualidade de serviços.

O 'Modelo Conceitual da Qualidade de Serviço' apresenta as situações em que podem ocorrer os Gaps entre as expectativas e percepções dos clientes. No modelo, fica explícito que a qualidade dos serviços é influenciada pelos comportamentos dos funcionários mediante as cinco dimensões: tangibilidade (tangibles), confiabilidade (reliability), sensibilidade/receptividade (responsiveness), segurança/garantia (assurance) e empatia (empathy).

Confiabilidade: A capacidade de prestar o serviço prometido de modo confiável e com precisão. Tangíveis: A aparência física de instalações, equipamentos, pessoal e materiais de comunicação. Sensibilidade: a disposição para ajudar o cliente e proporcionar com presteza um serviço. Segurança: O conhecimento e a cortesia de empregados e sua habilidade em transmitir confiança e confiabilidade. Empatia: A atenção e o carinho individualizados proporcionados aos clientes. (BERRY; PARASURAMAN, 1992, p. 30).

A dimensão Tangibilidade em bibliotecas acadêmicas, a atualização de equipamentos de informática (hardware e software) é relevante, por exemplo, para tornar ágeis as pesquisas dos clientes. Aparência também importa, pois afeta a percepção em relação à qualidade do serviço.

A dimensão Confiabilidade na perspectiva de um cliente de biblioteca acadêmica, confiabilidade é relevante, pois aponta à dependência obrigatória em relação aos serviços prestados pela instituição. Se o serviço não for prestado com precisão e no prazo estipulado, o usuário pesquisador pode incorrer em danos irreparáveis, como por exemplo, deixar de citar um texto proeminente por demora no serviço de empréstimo de acervo interbibliotecas. 
A dimensão Receptividade procede da categoria Sensibilidade, denota uma redução do tempo despendido pelo usuário em questões atinentes aos serviços de informação, ou seja, ofertando presteza no processo de pesquisa.

A dimensão Garantia sintetiza as categorias Competência, Cortesia, Comunicação, Credibilidade e Segurança. Nesta dimensão, é dado mais ênfase aos trabalhadores, em comparação com a dimensão Confiança, que se relaciona, no conjunto deste trabalho, com a qualidade de serviço da biblioteca acadêmica, enquanto instituição prestadora de serviços de informação.

Por fim, a dimensão Empatia concentra as categorias Acesso e Compreensão. Em bibliotecas acadêmicas, essa dimensão é relevante, pois cada pesquisa tem objetivos distintos; a forma de pesquisar e os conhecimentos atinentes às diversas possibilidades metodológicas para cada usuário. A satisfação é uma avaliação feita pelo cliente e acontece quando um serviço atende ou não as suas necessidades e expectativas.

Parasuraman, Zeithaml e Berry (1985) a satisfação dos clientes está diretamente ligada às suas percepções quanto à qualidade dos serviços. A falha em alcançar estas necessidade $\mathrm{e}$ expectativas é a causadora de insatisfação.

Diante da acepção de melhoria da qualidade dos serviços públicos de um modo geral, o reitor da Ufes, professor Reinaldo Centoducatte vem anunciando que a Universidade caminha para alcançar um padrão de excelência acadêmica em diferentes áreas do conhecimento, tendo como o objetivo primordial a busca da qualidade de todas as suas ações acadêmicas (META DA UFES É AMPLIAR A QUALIDADE, 2013, p.56).

Porém, conhecer o que as pessoas esperam é importante para definir ações. Nesse sentido, estabelecer um Plano de Ação para a Universidade dirigido à melhoria da qualidade de seus serviços e produtos significa que cada setor da Ufes deverá mapear as necessidades e conhecer o grau de satisfação das pessoas que atendem.

Com esse entendimento fomos autorizados a realizar este estudo de usuários para conhecer as expectativas e percepções da clientela da BSArtes. Para isso, adotamos a abordagem teórico-metodológica Servqual. Mas, por que denominamos o Servqual como uma abordagem teórico-metodológica? Porque fornece um corpus teórico sobre inúmeros conceitos, tais como: "qualidade, satisfação, percepção, expectativa, serviços, entre outros conceitos e, ao mesmo tempo, apresenta uma metodologia científica capaz de levar à concretização de estudos que tenham como objeto de estudo a satisfação dos usuários dos 
serviços prestados por quaisquer organizações" (CAMPOS; MIGUEL; CARVALHO, 2018, p. 87).

Tal abordagem torna viável avaliar a qualidade num cenário em que os serviços prestados podem variar. Cada indivíduo que constitui uma equipe de trabalho ${ }^{3}$ possui jeitos e características de acolher e recepcionar, modos de se colocar à disposição, de compreender, ser e fazer singulares.

\section{PROCEDIMENTOS METODOLÓGICOS}

A seguir serão explanados o percurso metodológicos, que compreendem: a caracterização do ambiente da pesquisa; as técnicas de pesquisa empregadas; a caracterização da população-alvo e amostragem; e as estratégias de coleta de dados empregadas na efetivação da pesquisa .

\subsection{AMBIENTE DE PESQUISA}

O estudo foi realizado na BSArtes - Biblioteca Setorial (BS) do Centro de Artes $(\mathrm{CAr})^{4}$ da Universidade Federal do Espírito Santo (Ufes). A BSArtes tem como objetivo principal dar suporte às atividades de ensino, pesquisa e extensão.

A Direção do CAr e o Conselho Universitário da Ufes, por meio da Comissão de Legislação e Normas, integrou a BSArtes ao Sistema Integrado de Bibliotecas da Ufes (SIB/Ufes $)^{5}$.O referido sistema é constituído por oito bibliotecas sendo que a Biblioteca Central Fernando de Castro Moraes (BC) o órgão coordenador do SIB. Cabe lembrar que o

\footnotetext{
${ }^{3}$ Assim é comum que cada colaborador tenha um desempenho diferenciado mesmo que a organização implante processos de padronização para alcançar a qualidade almejada

4 Os centros de ensino são unidades acadêmico-administrativas, o qual cabe o papel de zelar pelo desenvolvimento das atividades de ensino, pesquisa e extensão, em articulação com os cursos de graduação e as coordenações dos programas de pós-graduação. A Ufes possui 9 Centros: Centro de Artes (CAr), Centro de Ciências Agrárias (CCA), Centro de Ciências Exatas (CCE), Centro de Ciências Humanas e Naturais (CCHN), Centro de Ciências Jurídicas e Econômicas (CCJE), Centro de Ciências da Saúde (CCS),Centro de Educação (CE), Centro de Educação Física e Desportos (CEFD), Centro Tecnológico (CT).

5 Sistema Integrado de Bibliotecas (SIB) da Universidade Federal do Espírito Santo (Ufes) conta com oito unidades: Biblioteca Central (BC) Fernando de Castro Moraes [responsável por coordenar todo o Sistema], Biblioteca Setorial Tecnológica, Biblioteca Setorial Ciências da Saúde, Biblioteca Setorial do Centro Universitário Norte do Espírito Santo (Ceunes), Biblioteca Setorial de Ciências Agrárias, Biblioteca Setorial de Artes, Biblioteca Setorial de Educação do Centro de Educação (CE) e Biblioteca Setorial do Núcleo de Estudos e de Difusão de Tecnologia em Floresta, Recursos Hídricos e Agricultura Sustentável (Nedtec).
} 
SIB/Ufes possui oito unidades distribuídas nos quatro campi universitários, com um acervo de 438 mil exemplares e 143 mil títulos.

A BSArtes possui um acervo bibliográfico geral da graduação e um específico, gerado pelos Programas de Pós-graduação do Centro de Artes e ocupa uma área de 240 metros quadrados. Essa biblioteca oferece os seguintes serviços: empréstimo de livros e multimeios, empréstimo entre bibliotecas, renovação e reserva de livros e multimeios, acesso a periódicos, acesso ao portal de periódicos da CAPES. O horário de funcionamento é de segunda a sextafeira das 07:00 às 21:00 horas e faz, em média, 900 atendimentos mensais.

A BSArtes conta com um acervo de 7.819 títulos de livros; 121 títulos de dissertações com 136 exemplares; 58 teses; 367 monografias; 5 títulos de periódicos; 90 títulos obras de referência. Dentre as metas para futuro, a instituição busca o aumento do acervo, bem como a manutenção de sua atualidade.

\subsection{TÉCNICA DE PESQUISA}

Para a realização do Levantamento escolhemos como técnica de coleta de dados o questionário, mesmo porque o Método Servqual, o qual propõe uma escala avaliativa ${ }^{6}$ das cinco dimensões da qualidade em serviços. Não existe um número obrigatório de atributos, embora o mais comum seja usar as 22 questões sugeridas por Parasuraman, Zeithaml e Berry (1985). A operacionalização desse método se dá pelo cálculo da diferença entre as percepções de desempenho e as expectativas de serviço. Todavia, a literatura recomenda a adaptação à situação estudada, mantendo o cuidado para que a extensão do questionário não prejudique as respostas.

Em convergência com Crossno e colaboradores (2001), preferimos utilizar o termo "importância" ao invés de expectativas, proposto pelo método Servqual, porque essa abordagem teórico-metodológica permite ajustes e, também concordamos com a utilização realizada por Brito e Vergueiro (2011) os quais admitem que essa estrutura gera simplificação e facilitação, sendo assim, é mais fácil para o participante entender: "o quanto atendimento é

\footnotetext{
${ }^{6}$ A Escala Likert é uma escala psicométrica das mais conhecidas e utilizadas em pesquisas quantitativas, usada para avaliar o nível de concordância ou discordância com à mesma. Usualmente são usados cinco níveis de respostas, os clientes deveriam assinalar uma opção entre 1 e 5 da escala Likert (sendo que na escala $1=$ menos pertinente e $5=$ muito pertinente) para as 22 pares de questões (importância x satisfação).
} 
importante para você" do que "qual a sua expectativa em relação ao atendimento". Pela mesma razão, percepção foi substituída por satisfação na esquematização das questões.

\subsection{POPULAÇÃO-ALVO E AMOSTRA}

A população-alvo foi constituída pelo conjunto de usuários que utiliza os serviços da BSArtes (discentes de graduação e pós-graduação, técnicos e docentes do CAr) e a comunidade em geral. A amostra selecionada é não probabilística acidental, e reuniu 290 usuários aos quais foram aplicados o questionário adaptado da abordagem teóricometodológica Servqual.

\subsection{ESTRATÉGIAS DE COLETA DE DADOS}

Cabe observar que as sentenças adotadas no presente estudo podem não ter representado a totalidade de atributos relevantes ao julgamento da qualidade do serviço estudado. No entanto, como já tinha havido validação prévia nos estudos citados, admitiu-se que sua replicação conferiria certa segurança e praticidade na aplicação. A ilustração a seguir (Figura 1) sinaliza os cinco passos de check-up adotados nesse plano de trabalho. 
Figura 1 - Método de trabalho

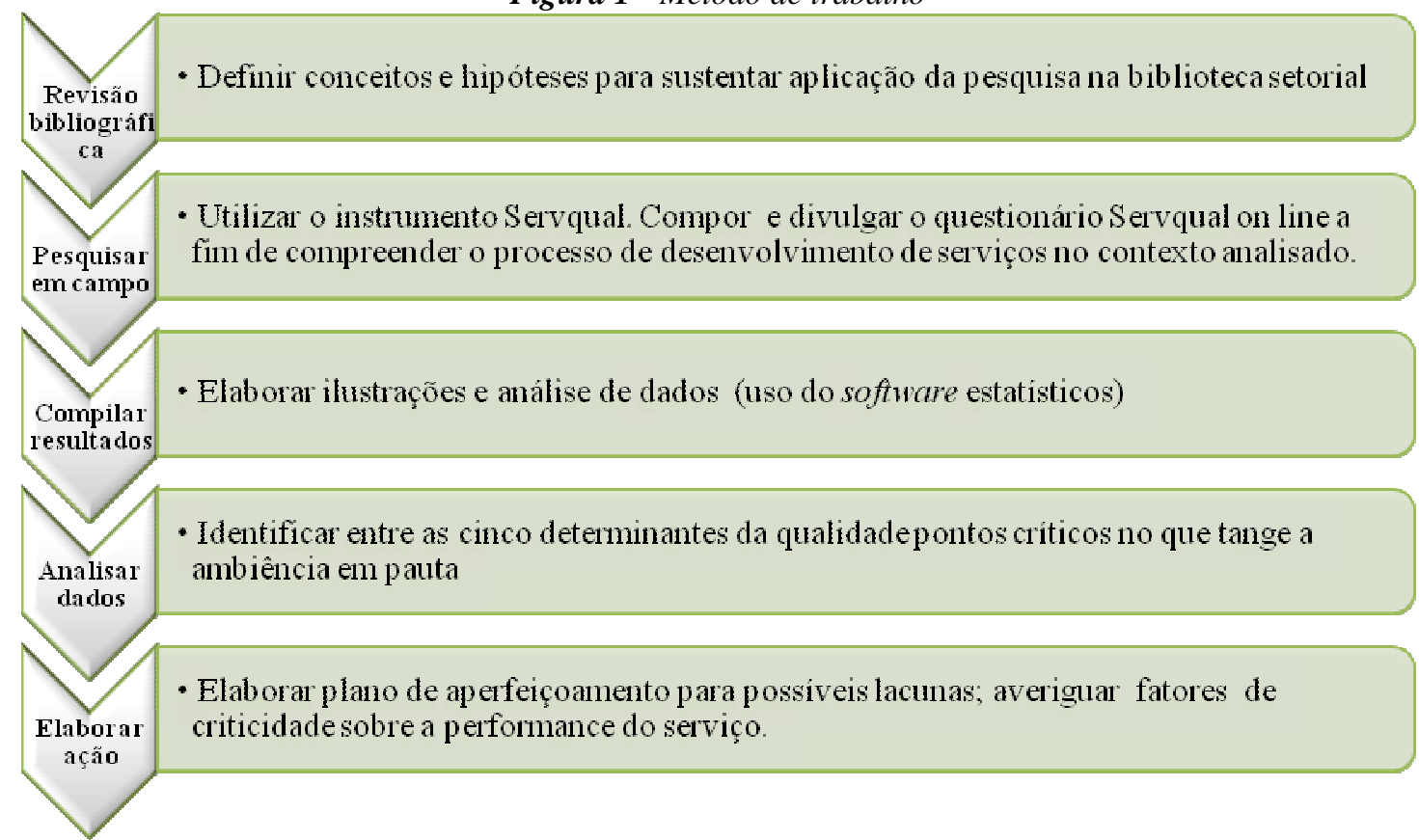

Fonte: os autores.

Como sempre ocorre a situação de coleta, apesar de cercada de cuidados para promover uma atmosfera adequada ao preenchimento do instrumento de pesquisa, não estava livre de interferências por isso disponibilizamos o questionário na internet para que os usuários pudessem acessá-lo a partir qualquer ambiente, objetivando facilitar o preenchimento e, consequentemente, o seu retorno.

O questionário online ${ }^{7}$ ficou disponível no período de 2 a 31 de maio de 2016 (período letivo) e os usuários foram convidados a participar da pesquisa (livre adesão). $\mathrm{O}$ procedimento de coleta de $\operatorname{dados}^{8}$ se deu de forma aleatória, com ampla divulgação, e o preenchimento do formulário avaliativo/métrico ocorreu conforme a disponibilidade da comunidade.

\footnotetext{
${ }^{7}$ Construído mediante a utilização da ferramenta Google Forms - do Google Docs. O Formulário Google pode ser conectado a planilhas e essas vinculadas a um formulário faz com que as respostas sejam automaticamente enviadas para a planilha. Pode-se criar um formulário a partir do Google Drive, disponível em <www.drive.google.com>.

${ }^{8}$ Os dados coletados foram inseridos e tabulados no programa Excel da Microsoft e utilizamos fórmulas estatísticas para calcular as médias, proporções, frequências relativas para produzir as tabelas e gráficos, visando facilitar a descrição dos dados recolhidos.
} 


\section{APRESENTAÇÃo E ANÁLISE DE DADOS}

Essa seção apresenta os resultados provenientes da investigação, os dados foram divididos, sintetizados e apresentados em dois blocos de análise, a saber: primeiramente as características gerais são apresentadas e, na sequência, aborda-se a análise lacunas pelo dimensionamento servqual.

\subsection{CARACTERÍSTICAS GERAIS}

No que remete ao gênero, do total de 290 respondentes, 190 (65,52\%) entrevistados indicaram o item feminino e $100(34,48 \%)$ masculino. Em termos de faixa etária, 200 $(68,97 \%)$ dos sujeitos na faixa etária de 18 a 24 anos. Destaca-se também a representatividade da faixa etária com 25 anos ou mais $(31,03 \%)$.

Em relação ao tipo de usuário da biblioteca, constatou-se que 250 (86,21\%) eram alunos da graduação sendo e destes: 182 (72,90\%) respondentes eram alunos do Curso de Artes Plásticas, Artes Visuais, Desenho Industrial/Design, Jornalismo, Arquitetura e Urbanismo, Música (Bacharelado e Licenciatura), Cinema e Audiovisual, e Publicidade e Propaganda - cursos localizado no próprio CAr; os outros 68 (27,20\%) respondentes corresponde a alunos matriculados em cursos fora do CAr como: administração, arquivologia, biblioteconomia, ciências sociais, engenharia, pedagogia, filosofia, geografia, história e letras. Destaca-se ainda a participação dos doutorandos 13 (4,48\%) e de 11 (3,39\%) mestrandos do Programa de Pós-Graduação em Arte (PPG-Arte) e 16 (5,52\%) alunos de cursos de especialização ofertados pela Ufes.

Quanto à frequência à biblioteca 127 (43,79\%) dos participantes comparecem à biblioteca ao menos uma vez por semana, 89 (30,69\%) participantes a frequentam ao menos uma vez por quinzena e outros $74(25,52 \%)$ participantes a frequentam ao menos mensalmente, frequência essa que pode ser considerada alta a julgar pelos prazos de devolução dos empréstimos da biblioteca, em geral, de quatorze dias podendo ser renovado pelo usuário desde que não esteja em atraso e que não haja solicitação de reserva.

Para fins de estruturação do texto, os dados são apresentados tomando-se como eixos as dimensões (empatia, garantia, receptividade, confiabilidade, tangibilidade) da qualidade 
que caracterizam o Método Servqual, as quais foram utilizadas também para a elaboração do instrumento de coleta de informações.

Tabela 1 - Importância e Satisfação por Dimensão

\begin{tabular}{ccc}
\hline & Importância & Satisfação \\
\hline Empatia & 4,34 & 3,79 \\
Garantia & 4,44 & 3,74 \\
Receptividade & 4,77 & 3,80 \\
Confiabilidade & 4,79 & 4,13 \\
Tangibilidade & 4,14 & 3,34 \\
\hline \multicolumn{2}{c}{ Fonte: Dados da pesquisa; Vitória/ES. }
\end{tabular}

Pode-se observar os graus de importância atribuídos pelos respondentes considerando as dimensões da qualidade, a saber: Confiabilidade $(4,79)$, seguida de Receptividade $(4,77)$, Garantia (4,44) e Empatia (4,34), sendo a menos valorizada foi a Tangibilidade (4,14). No que se refere à satisfação, observa-se que a dimensão mais valorizada pelos respondentes foi a Confiabilidade (4,13), seguida de Receptividade (3,80), Empatia (3,79) e Garantia (3,74). A dimensão com maior insatisfação é a Tangibilidade $(3,34)$ conforme a tabela 1 . De todas as dimensões, a confiabilidade mostrou ser o aspecto que os respondentes mais consideram ao avaliar um serviço.

\subsection{ANÁLISE DE GAPS E QUADRANTE}

Conforme Brito e Vergueiro (2011) há uma segunda maneira para apresentar os resultados de pesquisas que usam o método Servqual. Análise de Gaps compreende o diagnóstico dos Gaps apurado pelas questões das dimensões da qualidade. Para o cálculo dos Gaps, utiliza-se a seguinte equação: Gap = Satisfação - Importância

Para calcular as médias, as pontuações (de 1 a 5) de cada questão foram somadas e depois divididas pelo número total de respondentes (290) tanto para a satisfação quanto para a importância. A seguir foi calculada a diferença entre as duas, obtendo-se assim o Gap por 
questão. Também é possível verificar que o grau de exigência do público pesquisado é alto. A média das importâncias dadas pelos pesquisados às dimensões de qualidade variara entre 4,79 e 4,14 .

Assim sendo, estudos de Nitecki e Hernon (2000) indicam que as pontuações de Gaps entre 0 e -1 não superam as expectativas, porém podem atender ao que a comunidade usuária realmente esperam de um serviço de qualidade; logo pode-se dizer que a comunidade acadêmica do CAr percebe positivamente a qualidade dos serviços prestados pelo SR da BSArtes.

O maior Gap foi identificado na dimensão Receptividade $(0,97)$ e o menor é Empatia $(0,55)$. Entre os critérios que compõem as cinco dimensões, vimos que Confiabilidade apresenta maior importância $(4,79)$ e melhor satisfação $(4,13)$ e ainda, apresenta a segunda menor discrepância, tendo um de Gap $(0,66)$.

Para o cálculo dos Gaps por dimensão foram somadas as médias das questões de cada dimensão e divididas pelo total de questões de cada dimensão da qualidade do questionário da pesquisa. Por exemplo, para o cálculo dos Gaps da dimensão "Receptividade" foram somadas as médias das pontuações das questões relativas a esta dimensão e depois divididas por três, número das questões relacionadas a esta dimensão. O Gráfico 1 apresenta os Gaps por dimensão:

Gráfico 1 - Gaps por dimensões

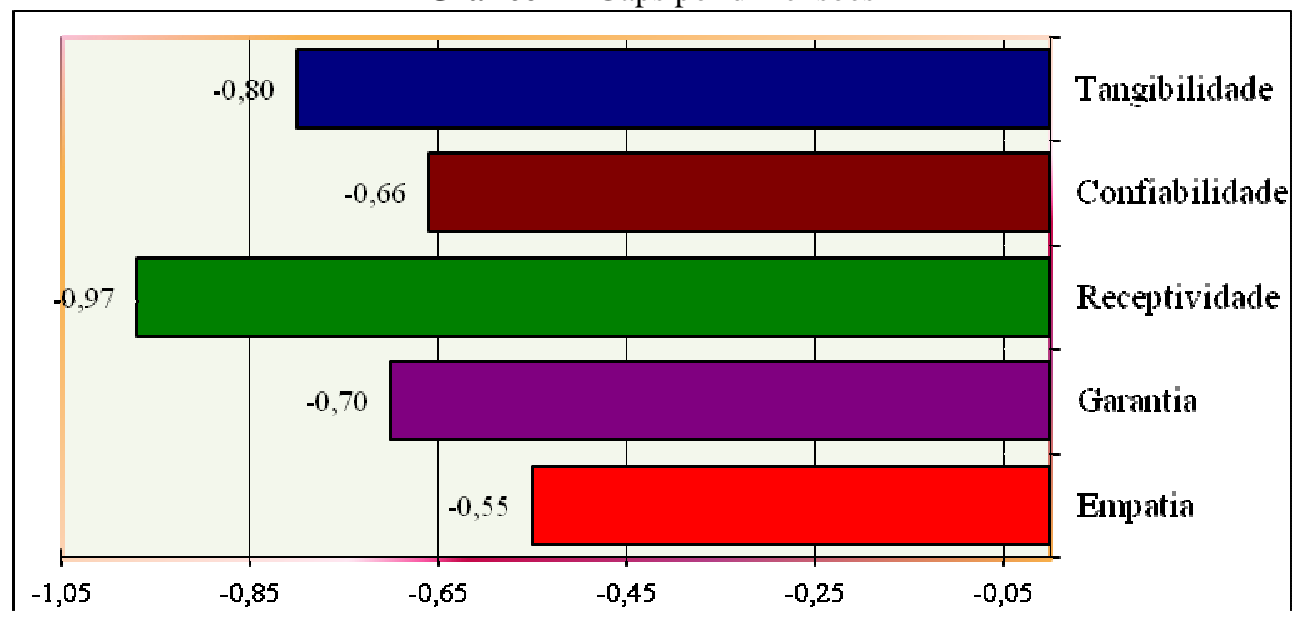

Fonte: Dados da pesquisa; Vitória/ES. 
A partir do Gráfico 1 pode-se deduzir que o item com o maior Gap na opinião dos participantes foi Receptividade, que de acordo com o método Servqual, refere-se a disposição para ajudar o usuário e fornecer um serviço com rapidez de resposta e presteza..

Matriz de Análise de Importância e Desempenho ${ }^{9}$, em geral designada Matriz Análise de Quadrantes, é recomendada por Nitecki e Hernon (2000) pois oferta uma correlação gráfica que facilita a visualização do diagnóstico.

A Matriz de Análise de Importância e Desempenho constitui-se uma ferramenta teórico-metodológica para que a instituição tenha uma visão estratégica sobre quais os atributos focalizar, para tornar-se mais competitiva no mercado. Observa-se que a análise de quadrantes é uma boa forma de se apresentar os resultados do método Servqual, como pode ser vislumbrado na Figura 2.

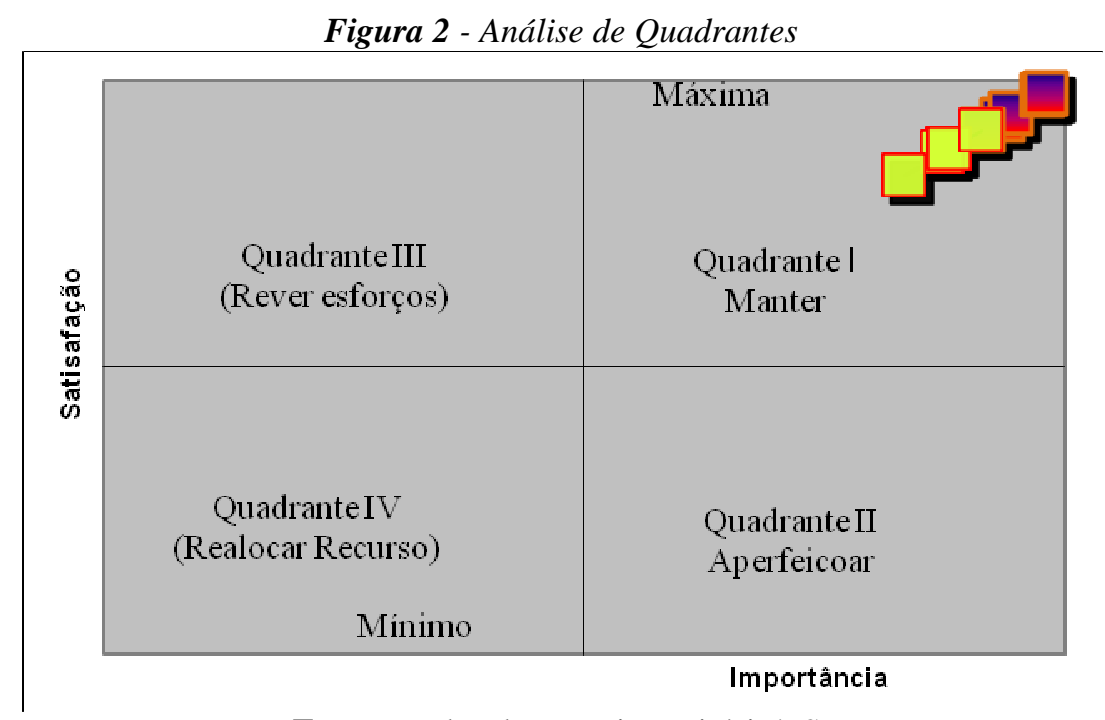

Fonte: Dados da pesquisa; Vitória/ES.

1. Ao aplicar a análise de quadrante verificam-se informações bastante interessantes sobre o SR da BSArtes e, nesta pesquisa ocorreu uma concentração no quadrante 1 (manter) de todos os vinte e dois atributos da qualidade. Isso sugere que

\footnotetext{
9 Matriz bidimensional, é dividida em quatro quadrantes: no Quadrante I os atributos situados tem alta importância com alto desempenho, representando uma possível vantagem competitiva. Um atributo que tiver alta importância, mas baixo desempenho, deverá receber atenção imediata, constando no Quadrante II. O Quadrante III concentra os atributos com alto desempenho, porém com baixa importância. O Quadrante IV contém os atributos com baixa importância e baixo desempenho, não sendo necessário concentrar esforço adicional.
} 
os clientes veem todos os atributos da pesquisa como importantes e bem desempenhados pela biblioteca setorial universitária.

\section{CONSIDERAÇÕES E RECOMENDAÇÕES}

Retomamos que objetivo principal dessa pesquisa foi avaliar a qualidade dos serviços prestados no que tange a expectativa e a percepção dos usuários em relação ao SR da BSArtes. Reiteramos que alguns resultados levam a inferir que algumas ações devem ser definidas pela biblioteca visando a melhorar a satisfação de seus usuários. Verificamos que se, de um lado, temos bons resultados no que concerne ao grau de confiabilidade por parte dos respondentes, do outro; faz-se necessário incrementar a dimensão Receptividade, pois a primazia do serviço deve estar pautada na boa capacidade de negociação, na liderança situacional e na habilidade de comunicação. Consideramos que a dimensão Receptividade está diretamente relacionada à dimensão Empatia, pois em se tratando de um SR, o conhecimento tácito do bibliotecário (know-how), na opinião dos respondentes o mesmo agrega valor ao atendimento ao zelar pelas necessidades do público e fornecer um serviço com presteza e rapidez de resposta.

Um dos pontos fracos refere-se a tangibilidade, demonstrando se que há necessidade de investir na melhoria da infraestrutura física e tecnológica, bem como no processo de humanização do acolhimento aos usuários por parte dos técnicos da Ufes. Esses resultados permitem sugerir que algumas ações específicas sejam consideradas, tais como: 1 implementar rede local sem fio, wi-fi. 2 - investir na melhoria da ambientação física, especialmente na climatização e ampliação do espaço físico; 3 - definir uma política de desenvolvimento de competências em informação, pois nem todos os usuários são autônomos na busca e recuperação da informação utilizando os sistemas informatizados ou serviços disponibilizados via web.

Esta pesquisa realizada para avaliar a qualidade do SR da BSArtes, a exemplo de outros realizados em bibliotecas acadêmicas, comprovou que realmente o método Servqual é apropriado para avaliar a qualidade a partir das percepções e expectativas dos usuários. Portanto, o método pode ser considerado ferramenta útil para a gestão e a tomada de decisões, pois permite evidenciar os pontos fracos e fortes das organizações sob a ótica da clientela. 
Em meio às vantagens do método em questão há uma desvantagem, qual seja: o questionário padrão do Servqual é constituído apenas por questões fechadas o que o caracteriza como um método quantitativo. Porém, nesta pesquisa, buscamos suprir essa lacuna inserindo questões abertas. Nessa direção, ao dar voz aos usuários também por essa via, além de agregarmos valor qualitativo ao estudo de usuários, reunimos informações explícitas que propiciam o monitoramento organizacional, hoje, tão significativo para o desenvolvimento das organizações.

O tema não foi esgotado e outras reflexões podem ser propostas; sugerimos explorar mais a parte qualitativa da abordagem teórico-metodológica Servqual promovendo métodos mais sofisticados de análise, envolvendo por exemplo, extensões/comparações de modelos e métricas (LibQUAL+ e SERVPERF, por exemplo). Portanto, possíveis desdobramentos podem fundamentar uma continuidade nessa linha de pesquisa.

Finalmente, cabe ressaltar que todo esse elenco de preocupações deve ser levado em consideração sem se perder de vista que a os modelos de avaliação da qualidade dos serviços nas bibliotecas universitárias são instrumentos essenciais de aferição de diagnósticos dos pontos fortes, fracos que podem exprimir em oportunidades de aplicabilidade de inovação e sustentabilidade, quando corretamente implementados e empregados, identificando causas e encontrando soluções criativas nas tomadas de decisão com vista a melhorar o desempenho na prestação de serviços em uma vasta gama da rede de bibliotecas acadêmicas.

\section{REFERÊNCIAS}

ACCART, J. P. Serviço de referência: do presencial ao virtual. Brasília, DF: Briquet de Lemos/Livros, 2012. 312 p.

ALMEIDA JÚNIOR, O. F. de. Biblioteca pública: avaliação de serviços. Londrina: EDUEL, 2003. $288 \mathrm{p}$.

ARAÚJO, C. A. Á. Estudos de usuários conforme o paradigma social da ciência informação: desafios teóricos e práticos de pesquisa. Informação \& Informação, Londrina, v. 15, n. 2, p. 23 - 39, jul./dez. 2010.

BRITO, G.; VERGUEIRO, W. Avaliação da qualidade orientada ao usuário: estudo de caso em biblioteca acadêmica utilizando o método SERVQUAL. Ciencias de la Información, La Habana, v. 42, n. 2, p. 55-59, mai./ago. 2011. Disponível em:

<http://www.redalyc.org/pdf/1814/181422294009.pdf>Acesso em: 08 mar. 2013. 
CAMPOS, A. C. B.; MIGUEL, M. C.; CARVALHO, S. M. S. de. Aplicação do modelo Servqual na bienal do livro da Zona da Mata: o olhar dos interagentes abrindo novas páginas para melhoria da qualidade. Encontros Bibli, Florianópolis, v. 23, n. 52, p. 84-94, maio 2018. ISSN 1518-2924. Disponível em: <https://doi.org/10.5007/1518-2924.2017v23n52p84>. Acesso em: 09 set. 2018.

CROSSNO, J. E. et al. Assessment of customer service in Academic Health Care Libraries (ACSAHL): an instrument for measuring customer service. Bulletin of the Medical Library Association v. 89, n. 2, p. 170-176, Abr. 2001. Disponível em: <http://www.ncbi.nlm.nih.gov/ pmc/articles/PMC31724/>. Acesso em: 17 mar. 2013

FERREIRA, S. M. S. P. Novos paradigmas e novos usuários de informação. Ciência da Informação, Brasília, v. 25, n. 2. 1995. Disponível em: <http://revista.ibict.br/ciinf/index.php/ciinf/article/download/440/398>. Acesso em: 02 fev. 2013

FIGUEIREDO, N. M. de. Paradigmas modernos da ciência da informação. São Paulo: Polis, 1999. $167 \mathrm{p}$.

FONSECA, E. N. da. Introdução á biblioteconomia. 2. ed. São Paulo: Briquet de Lemos, 2007, $152 \mathrm{p}$.

GONÇALVES, A. L. F. Gestão da informação na perspectiva do usuário: subsídios para uma política em bibliotecas universitárias. Niterói: Intertexto, 2013.

GROGAN, D. J. A prática do serviço de referência. Brasilia, DF: Briquet de Lemos/Livros, 1995. 196p.

LANCASTER, F. Wilfrid. Avaliação de serviços de bibliotecas. Tradução de Antonio Agenor. Brasília, DF: Briquet de Lemos, 1996. 356 p.

META DA UFES É AMPLIAR A QUALIDADE. Universidade: revista da Universidade Federal do Espírito Santo - UFES. Vitória (ES): UFES, n.1, p. 56-57, Jan/Abr, 2013. Quadrimestral.

NITECKI, D. A.; HERNON, P. Measuring service quality at Yale's University's libraries. The Journal of Academic Librarianship, Ann Arbor, v. 26, n. 4, p. 259-273, Jul. 2000.

PARASURAMAN, A; ZEITHAML, V. A; BERRY, L. L. A conceptual model of service quality and its implications for future research. Journal of Marketing, Chicago, v. 49, n. 4, p. 41-50, 1985.

RANGANATHAN, S. R. As cinco leis da biblioteconomia. Brasília: Briquet de Lemos, 2009. xxv, $336 \mathrm{p}$. 